\title{
On the minimum fluidization velocity in 2D fluidized beds
}

\author{
S. Sánchez-Delgado a,*, J.A. Almendros-Ibáñez ${ }^{\text {b,c }}$, N. García-Hernando ${ }^{a}$, D. Santana ${ }^{\text {a }}$ \\ a Universidad Carlos III de Madrid, ISE Research Group, Thermal and Fluid Engineering Department, Avda. de la Universidad 30, 28911 Leganés, Madrid, Spain \\ ${ }^{\mathrm{b}}$ Escuela de Ingenieros Industriales, Dpto. de Mecánica Aplicada e Ingeniería de Proyectos, Castilla La Mancha University, Campus Universitario s/n, 02071, Albacete, Spain \\ ${ }^{c}$ Renewable Energy Research Institute, Avda. de la Investigación s/n, 02071, Albacete, Spain
}

\begin{abstract}
A B S T R A C T
In the present study, a new correlation for the determination of the minimum fluidization velocity in $2 \mathrm{D}$ fluidized beds was developed. The proposed correlation was based on the experimental results obtained in 2D fluidized beds with different particle sizes, bed thicknesses and bed heights. Thus, the proposed correlation depends only on the nondimensional variable $t / d_{p}$, where $t$ is the bed thickness and $d_{p}$ is the particle size. The proposed correlation was compared with other experimental results that can be found in the literature, and two different trends were observed. Namely, one set of experimental results was in accordance with the proposed correlation, while the other set deviated from the theoretical results. In particular, the minimum fluidization velocities of the experimental results were greater than the predicted values of the proposed correlation. In view of the differences in the experimental conditions, the observed discrepancies may be attributed to the effects of electrostatic charge and particle shape. In addition, the experimental fluidization defluidization curves were compared to the theoretical results of Jackson's model, and the parameters were fitted to the experimental data. However, Jackson's model is based on a 1D bed; thus, general parameters could not be obtained for a bed with a fixed particle size and thickness due to the two dimensional voidage distribution in the bed and bed cohesion effects, which are a result of electrostatic forces and are not considered in Jackson's model.
\end{abstract}

\section{Introduction}

The study of fluidized beds dynamics is a complex task. Thus, different experimental techniques have been developed to evaluate the characteristics of fluidized beds, including pressure, capacitance, optical and/or heat transfer probes [1 3]. In addition, imaging techniques have been used to observe the interior of the bed. Simons [4] reviewed the use of radiation and capacitance imaging, and studies on the application of magnetic resonance imaging (MRI) for the determination of the time average particle velocity [5], time average voidage [6] and/or the mean length of jets in perforated plate distributors have been conducted [7].

Alternatively, 2D fluidized beds have been used to study fluidized bed hydrodynamics since the pioneering studies of the early 60's [8 11]. For example, Trsiakti et al. [12] and Pallarès and Johnsson [13] monitored the motion of an artificial fuel particle in a 2D fluidized bed with a camera to characterize fuel dispersion and fuel motion within the bed. In addition, Shen et al. [14] and Busciglio et al. [15] measured the size and velocity of bubbles along the height of the bed, and Santana et al. [16], Müller et al. [17] and Almendros Ibáñez et al. [18] applied Particle Image Velocimetry (PIV) to obtain the instantaneous

\footnotetext{
* Corresponding author. Tel.: + 34 916246223; fax: + 34916249430.

E-mail address: ssdelgad@ing.uc3m.es (S. Sánchez-Delgado).
}

particle velocity around erupting bubbles in 2D fluidized beds. Similarly, Almendros Ibáñez et al. [19] combined PIV techniques with numerical calculations to characterize particle fluid motion around bubbles, and Link et al. [20] and Busciglio et al. [21] compared the experimental results obtained in 2D fluidized beds to those of numerical simulations.

Thus, 2D fluidized beds have been successfully used to study particle fluid dynamics in fluidized beds, and important qualitative information has been obtained. Moreover, high speed video cameras can be easily employed in 2D fluidized beds [15 19], and higher spatial and temporal resolution than techniques commonly used in 3D beds (radiation and capacitance imaging and MRI) can be obtained. Nevertheless, it is unclear how the results obtained in 2D fluidized beds can be quantitatively extrapolated to 3D beds [22,23]. For instance, Geldart [24] and Clift [25] ] observed that the bubble size distribution in 2D fluidized beds could not be directly applied to 3D beds due to differences in bubble coalescence and the presence of wall effects. More recently, the experimental results of Shen et al. [14] corroborate these wall effects. In a different study, Briongos and Guardiola [26] proposed a new method based on chaos scale up techniques to scale 2D hydrodynamics.

The minimum fluidization velocity $U_{m f}$ is an important parameter of a fluidized bed. Ramos Caicedo et al. [27] fluidized glass ballotoni (density $\rho_{s}=2550 \mathrm{~kg} / \mathrm{m}^{3}$ particle size $d_{p}=250-400 \mu \mathrm{m}$ ) and demonstrated that the minimum fluidization velocity in 2D fluidized 
beds was dependent on the thickness and height of the bed. Thus, significant differences in the $U_{m f}$ (up to $500 \%$ ) were detected when the bed height was varied from $h=8 \mathrm{~cm}$ to $h=60 \mathrm{~cm}$ (bed thickness $t=6$ $\mathrm{mm}$ ). Ramos Caicedo et al. [27] proposed a correlation for the extrapolation of the $U_{m f}$ in 2D fluidized beds to the $U_{m f}$ of a 3D bed; however, the constant in the proposed correlation was dependent on the particle size. Thus, the correlation could not be used when different experimental conditions were applied. Moreover, Geldart [24] demonstrated that the minimum fluidization velocity increased with an increase in the fixed bed height; however, only a $43 \%$ increased in the $U_{m f}$ was observed when the bed height was increased from 5 to $80 \mathrm{~cm}$. In theory, the minimum fluidization velocity does not depend on the height of the bed; thus, the observed differences in the $U_{m f}$ were attributed to wall effects.

In the present study, a new correlation was proposed to quantify the effect of the 2D geometry on the minimum fluidization velocity, and the results indicated that the minimum fluidization velocity in a $2 \mathrm{D}$ bed increases with an increase in the ratio of the particle size to the bed thickness $\left(d_{p} / t\right)$ Alternatively, negligible differences were ob served when the fixed height of the bed was varied (in contrast to the results obtained by Ramos Caicedo et al. [27]). In addition, the proposed model by Jackson [28] was used to characterize wall effects; however, due to the $1 \mathrm{D}$ assumptions of the model (the voidage varies with the bed height $\varepsilon(z)$ ), general conclusions could not be obtained because the voidage distribution during the fluidization defluidiza tion process varies with the height and the width $(\varepsilon(x, z))$ of the bed.

In the following sections of the present manuscript, the experi mental set up and the particles employed in the experiments are described in detail. In addition, the experimental results are presented and discussed, and the main conclusions of the investigation are described in the final section.

\section{Experimental set-up}

The experiments were carried out in a 2D cold fluidized bed with a width $(w)$ and height $(H)$ of 500 and $2000 \mathrm{~mm}$ [29], respectively. The thickness of the bed $(t)$ was varied by adding or removing columns along the frame of the bed, and three different bed thickness were evaluated (5, 10 and $20 \mathrm{~mm}$ ). The gas flow was introduced through both sides of the plenum to properly distribute the gas flow. Fig. 1 shows a schematic depiction of the 2D bed.

Three different distributors were employed, and the type of distributor used in the bed was dependent on the bed thickness. The distributors consisted of perforated plates with $1 \mathrm{~mm}$ holes at $1 \mathrm{~cm}$ intervals. The ratio between the open area and the total area of the three distributors in each bed were identical, and the open area of the beds was set to $1.57 \%$ As a result, for all of the beds, the characteristic curves of the distributors $\left(\Delta P_{\text {dist }}-U\right)$ were identical. Fig. 2 (a) shows a schematic depiction of the distributors, and Fig. 2(b) shows the characteristic curves of the distributors.

The gas pressure drop was measured with a pressure transmitter (PTX 1400 model, GE industrial) at an operating pressure of $06 \mathrm{~atm}$. The transmitter was connected to a probe, which was situated in the plenum (see Fig. 1), and a sample frequency of $100 \mathrm{~Hz}$ was applied. Two types of particles with different sizes were employed in the present study, spherical glass particles with a density of $\rho_{p}=2500 \mathrm{~kg} /$ $\mathrm{m}^{3}$ (type B according to Geldart's classification [30]). Both particle size distributions were normal, and the mean particle size and standard deviation are shown in Fig. 3.

In addition to the 2D measurements, several measurements were obtained from a 3D bed that was similar to the one described in the literature [31]. These data were used to obtain the minimum fluidization velocity in a 3D bed.
A

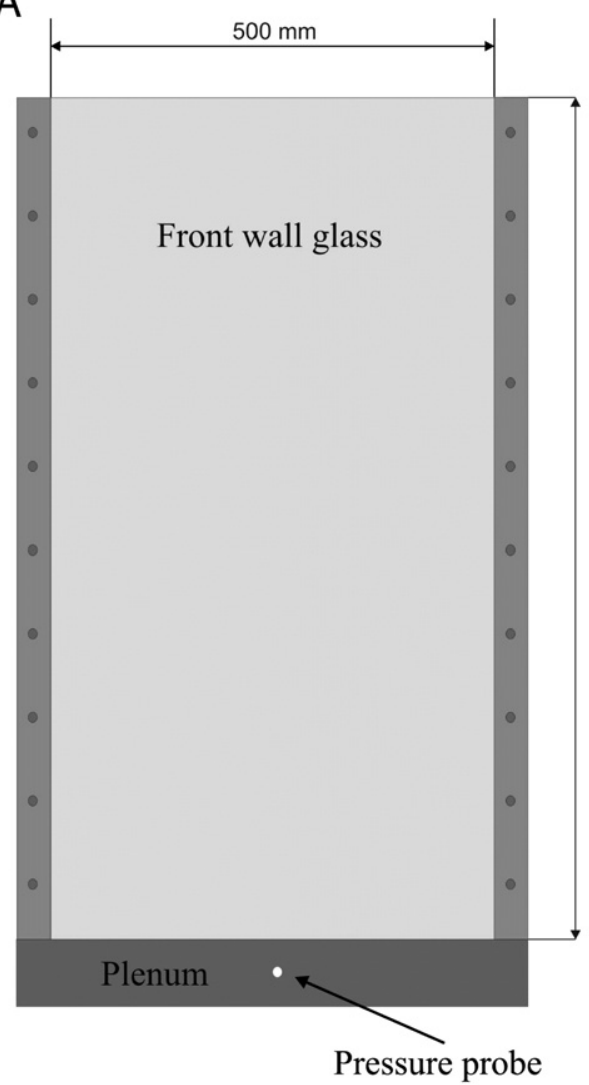

B

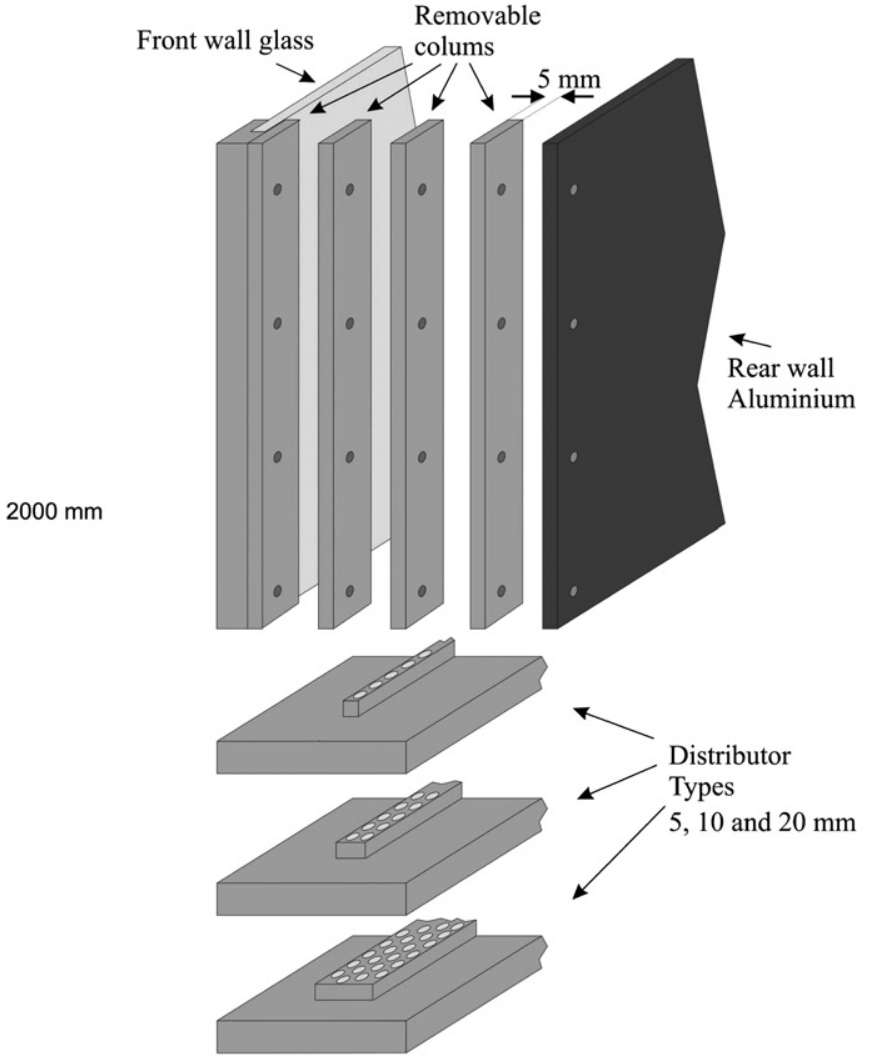

Fig. 1. Schematic depiction of the 2D fluidized bed. 

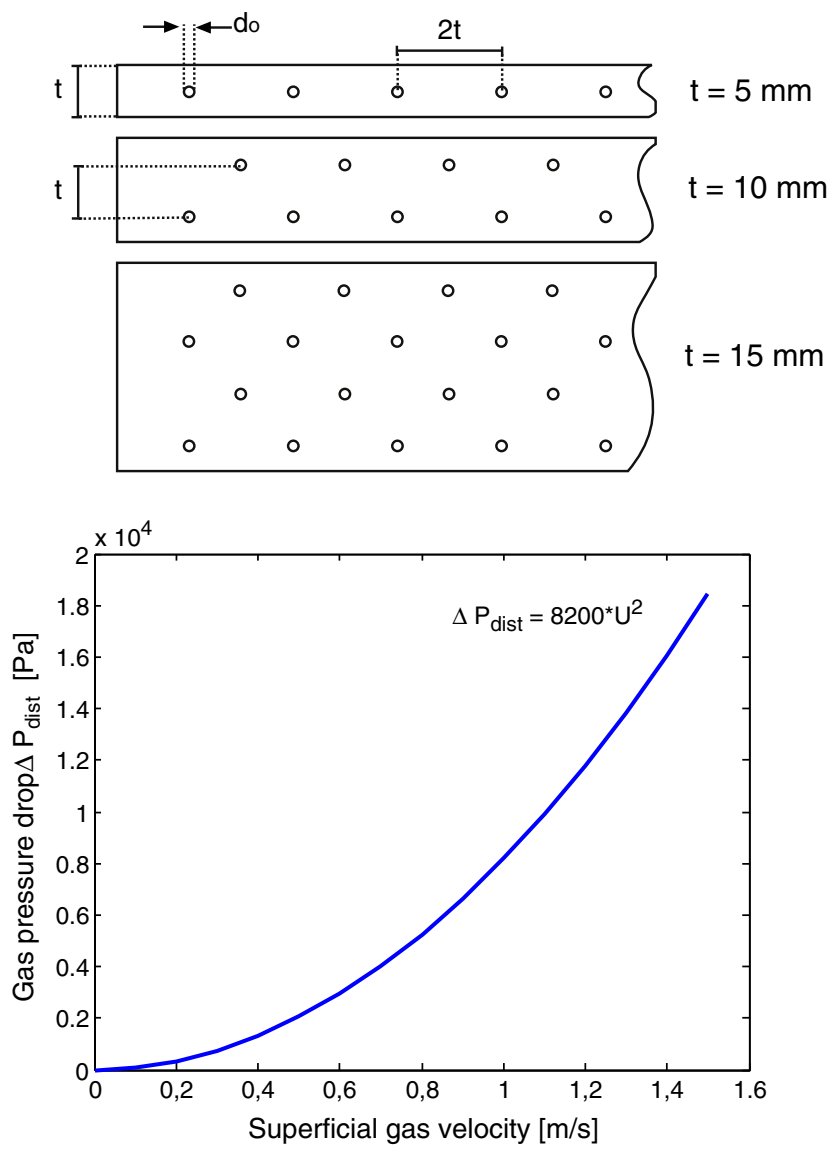

Fig. 2. (a) Distributor types and (b) characteristic curve of the distributor.

\section{Experimental results}

The two types of particles were fluidized in the 2D fluidized bed with different fixed heights and thicknesses. Bed heights of $0.1,0.2$ and $0.3 \mathrm{~m}$, were employed to obtain bed aspect ratios of $h / w=0.2,0.4$ and 0.6 , respectively. Moreover, bed thicknesses of $0.5,1.0$ and $2.0 \mathrm{~cm}$ were evaluated, and the same fluidization defluidization process was employed during each of the experiments. Namely, the bed was fluidized at a superficial gas velocity that was $1.2-1.5$ times greater than the minimum fluidization velocity, and the gas flow was progressively reduced until $U=0$. The bed was maintained under these conditions for $20 \mathrm{~min}$. Next, the gas flow was progressively

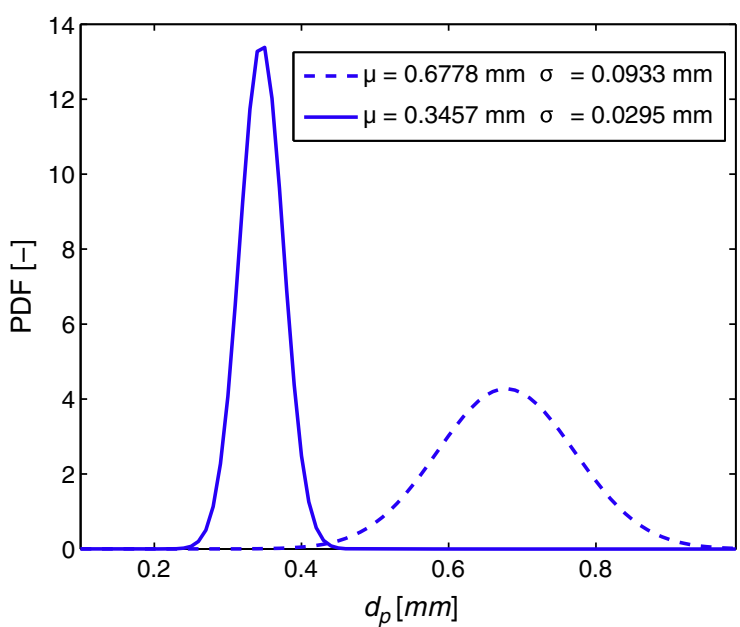

Fig. 3. Particle size distribution of the two types of particles used in the present study. increased until the bed was freely bubbling.The curve obtained under a decreasing gas flow was used to obtain $U_{m f}$, and the ascending curve was used to observe the hysteresis predicted by Jackson's model [28] which can be attributed to wall effects.

To measure the minimum fluidization velocity, the procedure described by Kathuria and Saxena [32] was employed. First, the pressure drop between the plenum and the outlet of the bed was measured at different superficial gas velocities to obtain the characteristic curve of the empty system, as described in the previous section. Next, the bed was filled with bed material, and the pressure was measured at different superficial gas velocities. In this way, the curve $\Delta P-U$ was obtained by subtracting the pressure drop of the empty system from the pressure drop of the filled bed, according to Eq. (1),

$\Delta P=\Delta P_{s+p}-\Delta P_{s}$

where $\Delta P_{s}$ is the gas pressure drop of the empty system, which was assumed to be approximately equal to the gas pressure drop through the distributor $\Delta P_{\text {dist }}$ (Fig. 2(b)), and $\Delta P_{s+p}$ was the gas pressure drop of the system when the bed was filled with particles.

Fig. 4 shows an example of the defluidization fluidization curve, for $d_{p}=345.7 \mu \mathrm{m}, h=10 \mathrm{~cm}$ and $t=0.5 \mathrm{~mm}$. In the figure, circles represent a decrease in the gas velocity, and squares represent a progressive increase in the gas velocity. The straight lines produced from the experimental results were used to obtain $U_{m f}$. The ascending curve was higher than the descending curve in the vicinity of $U_{m} f$, which is in agreement with the results of Jackson's model [28]. Overpressure in the fluidized bed is due to friction between the particles and the walls. During the fluidization process, the gas pressure drop must overcome the weight of the particles and particle wall friction, which results in overpressure. This effect should become more important as the distance between the walls decreases.

Table 1 shows the minimum fluidization velocities of each experimental bed, where the fixed bed height, bed thickness and particle size were varied. The minimum fluidization velocity was not affected by the fixed bed height because the effect of $h$ on the experimental results was small and was similar in magnitude to the uncertainty in the experimental measurements. Thus, a clear trend in the effect of $h$ on the minimum fluidization velocity was not observed. Theoretically, the minimum fluidization velocity is dependent on the properties of the particles and the gas, not the bed height. However, in previous studies [24,27] noticeable differences in the $U_{m f}$ of $2 \mathrm{D}$ fluidized beds were observed as the height of the fixed bed was

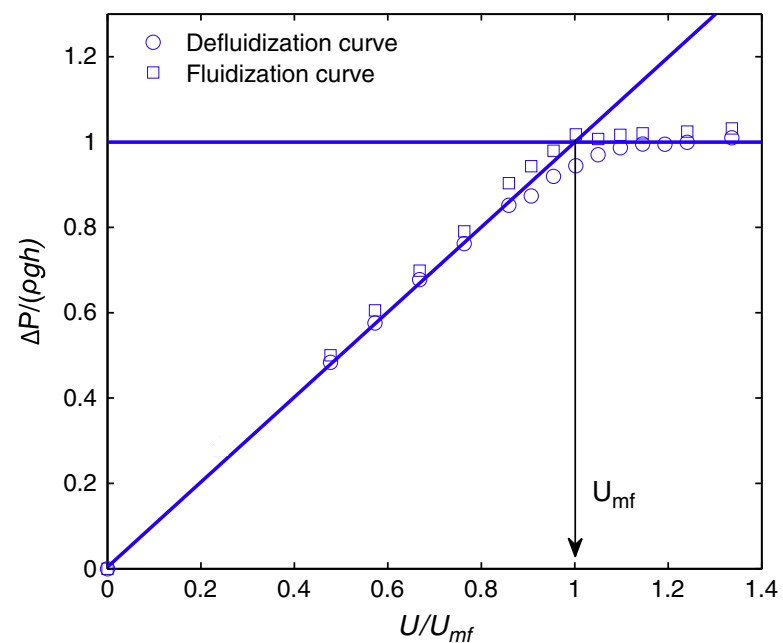

Fig. 4. Defluidzation-fluidization curve for $d_{p}=345.7 \mu \mathrm{m}, \mathrm{h}=10 \mathrm{~cm}$ and $t=0.5 \mathrm{~mm}$. 
Table 1

Minimum fluidization velocities in 2D fluidized bed. Units in $\mathrm{m} / \mathrm{s}$

\begin{tabular}{lllllll}
\hline & \multicolumn{6}{c}{ Thickness $t[\mathrm{~mm}]$} \\
\cline { 2 - 7 } & \multicolumn{7}{c}{10} \\
\cline { 2 - 7 } & 545.7 & 677.8 & 345.7 & 677.8 & 345.7 & 677.8 \\
\hline & 0.1403 & 0.3348 & 0.1234 & 0.2688 & 0.1241 & 0.2376 \\
$h=10 \mathrm{~cm}$ & 0.1406 & 0.3540 & 0.1230 & 0.2846 & 0.1165 & 0.2591 \\
$h=20 \mathrm{~cm}$ & 0.1366 & 0.3488 & 0.1366 & 0.2895 & 0.1197 & 0.2573 \\
$h=30 \mathrm{~cm}$ & 0.1366 & \\
\hline
\end{tabular}

increased. A possible explanation for this phenomenon will be discussed in the following section.

The minimum fluidization velocity of the two types of particles was measured in the 3D bed described in the previous section, and the same procedure used in the $2 \mathrm{D}$ bed was applied to the 3D bed. Table 2 shows the results of the 3D bed, together with the minimum fluidization velocity of the $2 \mathrm{D}$ beds. As shown in the table, the minimum fluidization velocity increased with a decrease in the thickness of the bed. This tendency was stronger when the largest particles were fluidized, which suggests that $U_{m f, 2 D}$ may be correlated to the nondimensional parameter $t / d_{p}$.

To obtain a general correlation for the ratio of $U_{m f, 2 D}$ to $U_{m f, 3 D}$ as a function of the mean particle size and bed thickness, Eq. (2) was proposed, which fulfills the condition that $U_{m f, 2 D}$ tends to $U_{m f, 3 D}$ when $t \gg d_{p}$. Eq. (2) was fitted to the data shown in Table 2, and the values of $a$ and $b$ were 8.5 and 1.6, respectively.

$\frac{U_{m f, 2 D}}{U_{m f, 3 D}}=\exp \left(a \cdot\left(\frac{d_{p}}{t}\right)^{b}\right)$

Fig. 5 shows the experimental data shown in Table 2 (represented by circles) the fit of the experimental results to Eq. (2), the results of other studies [15,23,24,32 35], (which are showed in Table 3), and the corresponding experimental conditions. Two sets of data obtained by Saxena and Jadav [33], which are represented by empty diamonds, were in accordance with the results of the proposed equation. The experimental data were based on spherical glass beds and red silica sand particles with a mean particle size of $d_{p}=427 \mu \mathrm{m}$ and $788 \mu \mathrm{m}$ respectively, and the thickness of the bed was equal to $t=1.57 \mathrm{~mm}$. In the study of Busciglio et al. [15], differences between the minimum fluidization velocity in a 2D bed and the results obtained from Ergun's equation were not observed; thus, a value of $U_{m f, 2 D} / U_{m f, 3 D}=1$ was assumed. In Fig. 5 the data obtained by Busciglio et al. [15] are represented by a cross. Alternatively, the data represented by an empty square (Rowe and Everett [23]) correspond to a bed with a thickness of $14.3 \mathrm{~cm}$, which fulfils the condition that $\lim _{d_{p} / t \rightarrow 0} U_{m f, 2 D}=U_{m f, 3 D}$. An additional data set obtained by Saxena and Jadav [33], which is represented by a filled diamond (silica sand with a mean particle size of $d_{p}=488 \mu \mathrm{m}$ ) deviated from the trends displayed by the other data sets. The authors suggested that the aforementioned discrepancy could be attributed to the fact that the friction between the wall and the sand particles (due to its non spherical shape) was greater than that of glass

Table 2

Minimum fluidization velocities in a $3 \mathrm{D}$ bed and the mean minimum fluidization velocities obtained in the $2 \mathrm{D}$ bed.

\begin{tabular}{llll}
\hline & & $U_{m f, 2 D}$ & $U_{m f, 3 D}$ \\
\hline $3^{*} d_{p}=345.7 \mu m$ & $t=5 m m$ & $0.1392 \mathrm{~m} / \mathrm{s}$ & $3^{*} 0.1244 \mathrm{~m} / \mathrm{s}$ \\
& $t=10 \mathrm{~mm}$ & $0.1277 \mathrm{~m} / \mathrm{s}$ & \\
$3^{*} d_{p}=677.8 \mu m$ & $t=20 \mathrm{~mm}$ & $0.1201 \mathrm{~m} / \mathrm{s}$ & \\
& $t=5 \mathrm{~mm}$ & $0.3459 \mathrm{~m} / \mathrm{s}$ & $3^{*} 0.2446 \mathrm{~m} / \mathrm{s}$ \\
& $t=10 \mathrm{~mm}$ & $0.2810 \mathrm{~m} / \mathrm{s}$ & \\
& $t=20 \mathrm{~mm}$ & $0.2513 \mathrm{~m} / \mathrm{s}$ & \\
\hline
\end{tabular}

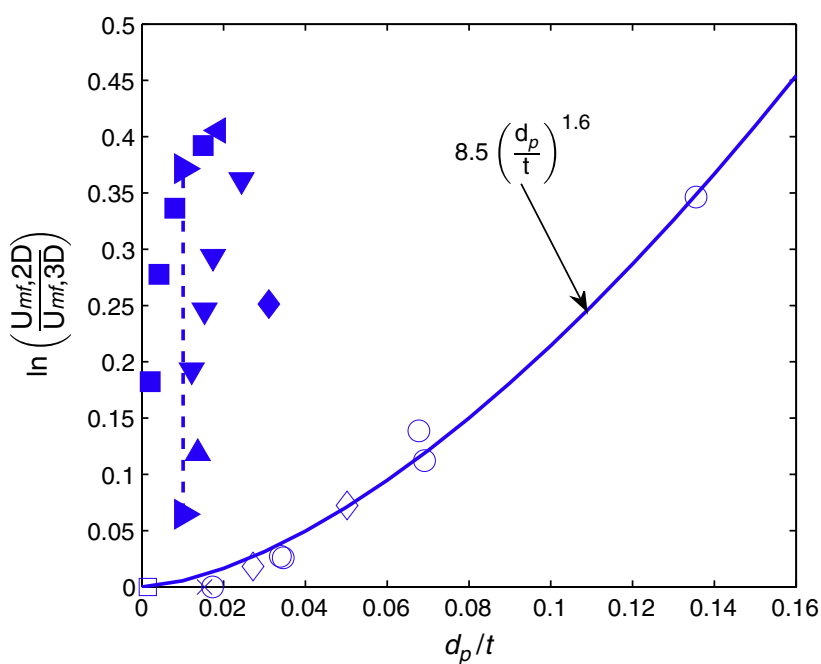

Fig. 5. Plots of $\ln \left(U_{m f, 2 D} / U_{m f, 3 D}\right)$ vs. $d_{p} / t$ for the experimental results of different studies. The solid line represents the fit of Eq. (2) to the experimental data obtained in the present study, the circles represent the experimental data of the current investigation and the dashed line represents the results obtained by Geldart [24] who varied the bed height $h$ at a constant $d_{p} / t$. $O=$ data obtained in the present study (Table 2), $\times=$ data obtained by Busciglio et al. [15], $\diamond=$ data obtained by Saxena and Jadav [33], $\square=$ data obtained by Rowe and Everett [23], $\mathbf{\nabla}=$ data obtained by Kathuria and Saxena [32], data obtained by Saxena and Jadav [33], $\boldsymbol{\Delta}=$ data obtained by Glicksman and McAndrews [34], $\mathbf{4}=$ data obtained by Mudde et al. [35], $>=$ data obtained by Geldart [24], = data obtained by Rowe and Everett [23].

beds with a similar size. Finally, the dashed line represents the data obtained by Geldart [24] who studied the variation in $U_{m f, 2 D}$ at fixed bed heights of $580 \mathrm{~cm}$, and maintained a constant particle size and bed thickness. The other data $[23,32,34,35]$ shown in Fig. 5 were not in agreement with the results of the proposed equation.

As shown in Fig. 5 a group of experimental data sets (represented by filled symbols) were not in agreement with the experimental results of the present study (represented with circles) and those of previous investigations (represented by empty symbols and a cross). Some of the deviations in the experimental results were unexpected. For instance, in the results obtained by Rowe and Everett [23], which are represented by filled squares and corresponded to fluidized particles with a $d_{p}$ of $210 \mu \mathrm{m}$ and beds with a thickness of $1.4,2.6,5.0$ and $10.2 \mathrm{~cm}$, respectively, deviations were not observed until the bed thickness reached $14.3 \mathrm{~cm}$ At this point, which is represented by an empty square, wall effects did not influence the minimum fluidization velocity. An explanation for these discrepancies will be discussed in the following section.

\section{Discussion}

\subsection{Wall effects during the defluidization fluidization process}

Wall effects on the defluidization fluidization curves, including friction between the particles and the walls of the bed, have been modeled by Jackson [28,37]. A complete description of the model can be found in the literature [28,37], and the model can be summarized as follows.

The general momentum equation of a group of static particles confined by walls in the presence of a gas percolating can be reduced to:

$\frac{d \sigma_{s}}{d z}=-\frac{\rho_{s} g u_{g}}{v_{t}} \frac{\phi}{(1-\phi)^{n}} \pm \frac{4}{D_{h}} \mu j \sigma_{s}+\phi \rho_{s} g$.

where $\sigma_{s}$ is the compressive yield stress of the particles, $z$ is the vertical coordinate of the surface of the bed, $g$ is the gravity, $u_{g}$ is the interstitial gas velocity, $v_{t}$ is the terminal velocity of the particles, $\phi$ is 
Table 3

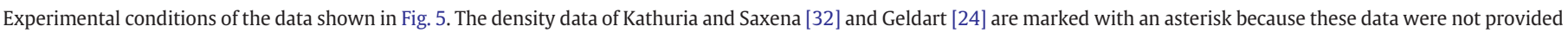
by the authors. The particles were categorized according to the classification system proposed by Grace [36].

\begin{tabular}{|c|c|c|c|c|c|c|c|c|}
\hline Data & Authors & Particles & $\mathrm{d}_{\mathrm{p}}[\mu \mathrm{m}]$ & $\rho_{\mathbf{s}}\left[\frac{\mathrm{kg}}{\mathrm{m}^{3}}\right]$ & Type & $t[\mathrm{~mm}]$ & Walls material & $\frac{U_{m f, 2 D}}{U_{m f, 3 D}}$ \\
\hline \multirow[t]{6}{*}{ ○ } & This work & Glass spheres & 345.7 & 2500 & B & 5.0 & Glass & 1.12 \\
\hline & & & & & & 10.0 & & 1.03 \\
\hline & & & & & & 20.0 & & 1.00 \\
\hline & & & 677.8 & & & 5.0 & & 1.41 \\
\hline & & & & & & 10.0 & & 1.15 \\
\hline & & & & & & 20.0 & & 1.03 \\
\hline$\times$ & Busciglio et al. [15] & Glass ballotoni & 215 & 2500 & B & 15.0 & Glass & 1.00 \\
\hline \multirow[t]{2}{*}{$\diamond$} & Saxena and Jadav [33] & Glass spheres & 427 & 2490 & B & 15.7 & Glass & 1.02 \\
\hline & & Sand & 788 & 2670 & B & & & 1.08 \\
\hline$\square$ & Rowe and Everett [23] & Alumina & 210 & - & - & 143.0 & - & 1.00 \\
\hline$\bullet$ & Saxena and Jadav [33] & Sand & 488 & 2670 & B & 15.7 & Glass & 1.29 \\
\hline \multirow[t]{4}{*}{ घ } & Rowe and Everett [23] & Alumina & 210 & - & - & 14.0 & - & 1.48 \\
\hline & & & & & & 26.0 & & 1.40 \\
\hline & & & & & & 50.0 & & 1.32 \\
\hline & & & & & & 102.0 & & 1.20 \\
\hline$\Delta$ & Glicksman and McAndrews [34] & Sand & 1040 & 2640 & $\mathrm{D}$ & 76.0 & Plexiglass & 1.13 \\
\hline \multirow[t]{4}{*}{$\boldsymbol{\nabla}$} & Kathuria and Saxena [32] & Sand & 774 & 2650 & B & 31.7 & Plexiglass & 1.44 \\
\hline & & & & & & 44.4 & & 1.34 \\
\hline & & & & & & 50.4 & & 1.28 \\
\hline & & & & & & 63.5 & & 1.21 \\
\hline \multirow[t]{2}{*}{4} & Mudde et al. [35] & Polystyrene spheres & 560 & 1102 & $\mathrm{~B}$ & 30.0 & Perspex & 1.50 \\
\hline & Geldart [24] & Sand & 128 & 2650 & $\mathrm{~B}$ & 12.7 & Perspex & $1.07-1.45$ \\
\hline
\end{tabular}

the particle concentration, $D_{h}$ is the hydraulic diameter, $\mu$ is the friction coefficient and $j$ is the Janssen's coefficient. In Eq. (3) the second term on the right side of the equation is positive when the particles are being fluidized.

The compressive yield stress $\sigma_{s}$, is expected to increase monoton ically with an increase in the particle concentration, $\phi$. Thus, Jackson $[28,37]$ proposed the following expression:

$\sigma_{s}=\left\{\begin{array}{lll}F \frac{\phi-\phi_{\min }}{\phi_{\max }-\phi} & \text { if } & \phi_{\min } \leq \phi \leq \phi_{\max } \\ 0 & \text { if } & \phi<\phi_{\min }\end{array}\right.$

where $F$ is a constant that can be adjusted experimentally and $\phi_{\min }$ and $\phi_{\max }$ are the minimum and maximum particle concentration, respectively. For the defluidization branch, Eq. (3) can be restructured as follows

$\frac{\partial \phi}{\partial z}=\frac{-\frac{\rho_{s} g u_{g}}{v_{t}} \frac{\phi}{(1 \phi)^{n}}-\frac{4}{D_{h}} \mu j \sigma_{s}+\phi \rho_{s} g}{\frac{\partial \sigma_{s}}{\partial \phi}}$,

where $\partial \sigma_{s} / \partial \phi$ can be obtained from Eq. (4). Eq. (5) can be integrated numerically to obtain the voidage distribution along the height of the bed. The integration starts at $z=0$ (free surface of the bed), where $\sigma_{s}=0\left(\phi=\phi_{\min }\right)$ and finishes at $z=h$ (the bottom of the bed), where the following condition must be fulfilled:

$A \rho_{s} \int_{0}^{h} \phi(z) d z=m$,

where $m$ is the mass of particles in the bed.

Table 4

The parameters of Jackson's model for the data shown in Fig. 6.

\begin{tabular}{ll}
\hline Parameters & Values \\
\hline$F$ & $2500 \mathrm{~N} / \mathrm{m}^{2}$ \\
$\phi_{\min }$ & 0.54 \\
$\phi_{\max }$ & 0.56 \\
$\rho_{s}$ & $2500 \mathrm{~kg} / \mathrm{m}^{3}$ \\
$n$ & 2 \\
$J_{d f}$ & $1000 \mathrm{~m}^{1}$ \\
$J_{f}$ & $800 \mathrm{~m}^{1}$ \\
\hline
\end{tabular}

Once the voidage distribution along the bed is known, the gas pressure drop along the height of the bed can be obtained from Eq. (7)

$\Delta p_{g}=\frac{u_{g} \rho_{s} g}{v_{t}} \int_{0}^{h} \frac{\phi}{(1-\phi)^{n}} d z$

For the fluidization process, Eq. (3) can be rewritten as:

$\frac{u_{c}}{v_{t}}=\frac{\int_{0}^{h} \phi e^{J z} \mathrm{~d} z}{\int_{0}^{h} \frac{\phi}{(1 \phi)^{n}} e^{J z} d z}$.

where $J=\left(4 / D_{h}\right) \mu j$, and $u_{c}$ is the critical gas velocity (maximum interstitial gas velocity of undisturbed particles) The particle concentration (or voidage) was assumed to be equal to the particle concentration at the end of the defluidization process $\phi(z)=\left.\phi(z)\right|_{u_{g}=0}$.

Eqs. (4) (8) suggest that hysteresis and overpressure will be observed due to wall effects in fluidized beds with small diameters, as observed in previous studies [38 40]. For instance, wall effects were observed by Srivastava and Sundaresan [38] and Loezos et al. [39], who studied fluidized particles in cylindrical beds with internal diameters of 10 and $50 \mathrm{~mm}$. In addition, wall effects were also observed by Liu et al. [40] , who used microfluidized beds with internal diameters ranging from 12 and $32 \mathrm{~mm}$. Alternatively, in the present study, Jackson's model was adjusted to the experimental data obtained in a $2 \mathrm{D}$ bed.

In this way, the value of the coefficient $n$ was fitted to the experi mental data using the methodology of Srivastava and Sundaresan [38] and Loezos et al. [39]. The value of $\phi_{\min }$ was assumed to be equal to the average particle concentration under minimum fluidization condi tions, $\phi_{m f}$, which was estimated by measuring the mass of the particles in the bed and the fixed bed height. According to the work of Srivastava and Sundaresan [38] and Loezos et al. [39], two different J values were used in the present study. Namely, $J_{d f}$, was used for the defluidizaton curve, and $J_{f}$ was used for the fluidization process. The value of $J_{f}$ was obtained was obtained from Eq. (8), where $u_{c}$ is known, and $J_{d f}$ and $\phi_{\max }$ were optimized to fit the experimental data. Table 4 summarizes the values of the parameters for each experiment, and Fig. 6 shows the experimental data and the theoretical results of Jackson's model. As shown in the figure, hysteresis was observed during the fluidization process. 


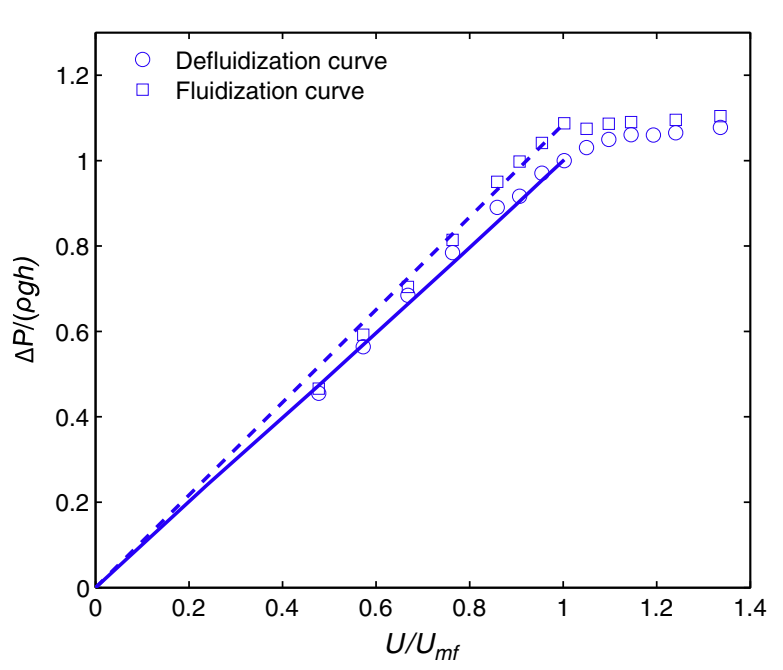

Fig. 6. Fluidization-defluidization curve for $d_{p}=345.7 \mu \mathrm{m}, h=10 \mathrm{~cm}$ and $t=0.5 \mathrm{~mm}$. The solid and dashed lines represent the theoretical results of Jackson's model for the defluidization and fluidization processes, respectively.

The optimal values of $J_{f}, J_{d f}$ and $\phi_{\max }$ are different for each experiment. For example, Fig. 7 displays the experimental results shown in 6; however, in Fig. 7, the fixed bed height was varied from $h=10 \mathrm{~cm}$ to $h=30 \mathrm{~cm}$. Using the values shown in Table 4, the results of Jackson's model were plotted in Fig. 7. As shown in the figure, Jackson's model does not properly represent the experimental results; thus, general values for a fixed particle size and bed thickness could not be obtained.

The discrepancies between the experimental and theoretical results could be attributed to the application of a 1D model $(\phi=\phi$ $(z))$ in a 2D bed, where the voidage distribution is clearly bidimen sional $(\phi=\phi(z, x)$ where $x$ the horizontal coordinate). In a two dimensional bed, if the distributor pressure drop is high enough, bubbles appear along the length of the distributor. However, coalescence along the height of the bed forces the bubbles to move toward the center of the bed. Thus, the sides of the bed are completely free of bubbles, as shown in Fig. 8. ${ }^{1}$ Due to the continuous bubble path in the central region of the bed, when the gas flow is reduced under minimum fluidization conditions, the local porosity of this region is greater than that of the sides of the bed. As a result, when the fixed bed is fluidized (when $U$ progressively increases from zero to $U_{m f}$ ), the voidage distribution along the bed is not uniform, and the gas preferably percolates through the central region of the bed, where the particle density is low. Fig. 8(B) shows a schematic depiction of the voidage profile and the preferential gas flow during fluidization, which was perpendicular to the constant voidage profile. As shown in the figure, the voidage was higher in the center and top of the bed.

The aforementioned effects were observed when the particles were fluidized in a bed with a large fixed height, as shown in the series of photographs displayed in Fig. 9 shows. For instance, as shown in Fig. 9(A) small bubbles were observed in the upper middle region of the bed, which was less compacted than the sides of the bed; however, the rest of the bed remained undisturbed. A slight increase in the gas velocity caused the bubbles to grow in size and appear from deeper regions of the bed (see Fig. 9(B)). Finally, bubbles were observed between the distributor and the surface of the bed. However, the bubbles only appeared in the central region of the bed (see Fig. 9(C)) because the central region was more permeable to gas flow. Alternatively, as shown in Fig. 9(C), the sides of the bed were free of bubbles. Nevertheless, if the gas flow is further increased, bubbles will appear along the width of the bed. However, for a gas

\footnotetext{
${ }^{1}$ Depending on the ratio between the height and width of the bed, different bubble paths were observed [41].
}

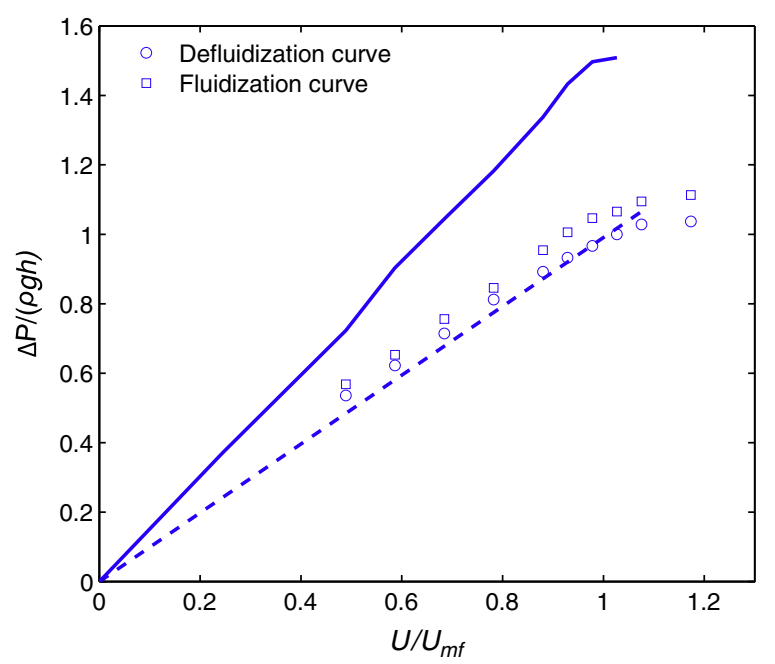

Fig. 7. Fluidization-defluidization curve for $d_{p}=345.7 \mu \mathrm{m}, \mathrm{h}=30 \mathrm{~cm}$ and $t=0.5 \mathrm{~mm}$. The solid and dashed lines represent the theoretical results of Jackson's model for the defluidization and fluidization process, which were obtained with the values shown in Table 4 , respectively.

velocity close to $U_{m f}$, gas tends to percolate through the central region of the bed due to the lower resistance of the central region to gas flow.

The one dimensional assumption of Jackson's model implies that $U$ is uniform throughout the bed and $\phi=\phi(z)$. The experimental observations of the present study revealed that these assumptions limit the applicability of the model in 2D beds. Nevertheless, wall effects and hysteresis were observed in some experiments (Fig. 6). Moreover, wall effects on the minimum fluidization velocity were clearly observed in Fig. 5 , due to the nondimensional variable $d_{p} / t$. Namely, as the ratio between the particle size and the thickness of the bed decreased, the minimum fluidization velocity increased.

\subsection{Discussion of the results shown in Fig. 5}

As shown in Fig. 5, the minimum fluidization velocities obtained in different studies were not in agreement. For instance, the experi mental results of the present study, along with the data marked by an empty symbol or a cross, were in accordance with the proposed exponential relationship between $U_{m f, 2 D}$ and $U_{m f, 3 D}$ (Eq. (2)). Alter natively, results marked with filled symbols clearly departed from the

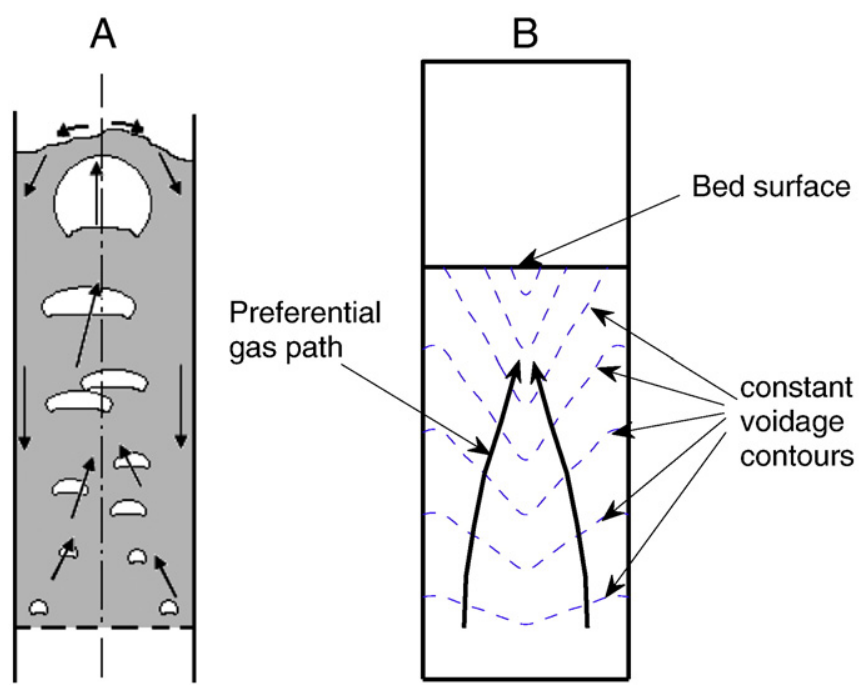

Fig. 8. (A) Schematic depiction of the movement of bubbles during free bubbling. The arrows indicate the direction of movement. (B) Schematic depiction of the constant voidage profiles and the gas path in the bed during the fluidization process. 


\section{(A) $U=0.14 \mathrm{~m} / \mathrm{s}$}

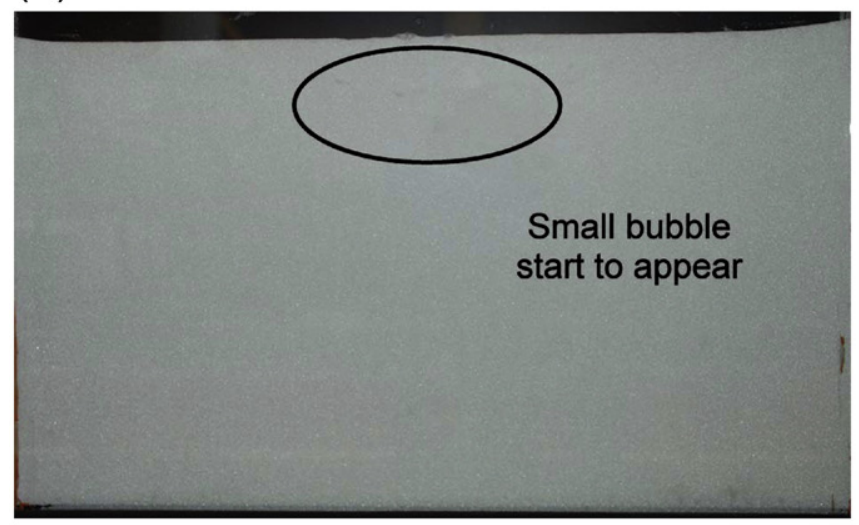

(B) $U=0.147 \mathrm{~m} / \mathrm{s}$

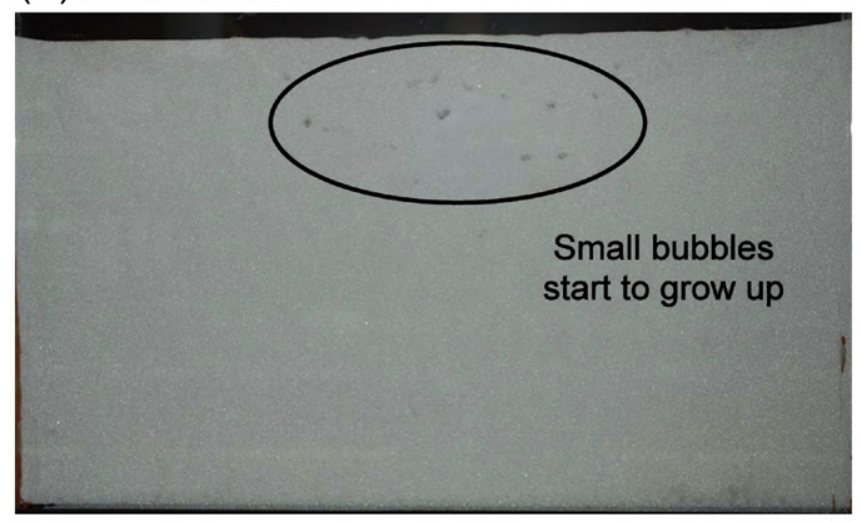

(C) $U=0.16 \mathrm{~m} / \mathrm{s}$

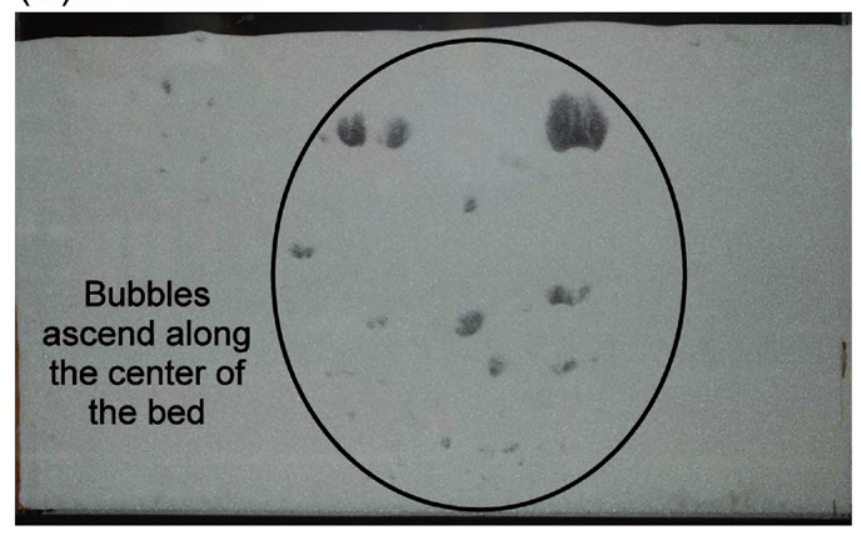

Fig. 9. Photographs captured during fluidization in a bed with $d_{p}=345.7 \mu \mathrm{m}, \mathrm{h}=30 \mathrm{~cm}$, $t=5 \mathrm{~mm}$.

proposed equation, and the values of $U_{m f, 2 D}$ were significantly higher when the particle size to thickness ratio was between 0 and 0.04 .

The discrepancies between the experimental data and the theoretical results are too high to be attributed to uncertainties in the experimental measurements or to the variety of experimental techniques used in the studies. Nevertheless, as shown in Table 3, all of the experimental data that were in accordance with the proposed correlation (Eq. (2)) were obtained in 2D beds with walls made of glass. An exception to the aforementioned observation is the data obtained by Rowe and Everett [23],which is marked with an empty square. However, based on the thickness of the bed, the study conducted by Rowe and Everett can be considered a 3D experiment. In addition, although Busciglio et al. [15] used a bed made from perspex, the walls of the bed were in direct contact with fluidized particles, which were made of glass to avoid electrostatic charge interactions. As a result, the particles were deposited on the surface of the walls, which precluded the proper observation of the interior of the bed. Alternatively, Saxena and Jadov [33] ground the walls of the bed to ensure that static charge did not accumulate on the surface of the walls. In the present study, problems associated with electrostatic charge were not observed during the experiments.

In contrast, the rest of data were obtained in 2D beds made of plastic materials (either perspex or plexiglass). Under these condi tions, electrostatic charge could have a significant effect on the fluidization velocity. Moreover, Mudde et al. [35] fluidized plastic particles, and obtained the highest velocity ratio $\left(U_{m f, 2 D} / U_{m f, 3 D}=1.5\right)$ of all of the data shown in Table 3, for the bed thickness of $t=30 \mathrm{~mm}$. The exception to the aforementioned observations is marked with a filled diamond. However, this data set departs from the other data obtained by the same authors. As previously mentioned, Saxena and Jadav [33] attributed the discrepancies in this data set to differences in particle geometry.

Electrostatic charge in fluidized beds is a complex phenomenon and is dependent on a number of variables [42 46], including the bed height, particle size, fluidization velocity, relative humidity of the fluidizing air, etc. The results of Rojo et al. [42] revealed that the electrostatic charge increases with an increase in the height of the fixed bed under bubbling conditions, which may explain the fact that an increase in the minimum fluidization velocity with an increase in bed height was observed by Ramos et al. [27] and Geldart [24]. Moreover, Guardiola et al. [43] observed that electrification increased with an increase in particle size and air velocity and suggested that the relative humidity of the air was an important parameter. Similarly, in a study conducted by Park et al. [44],the electrostatic charge of glass and polyethylene particles was reduced when the humidity of the fluidizing air was between 40 and $80 \%$ Alternatively, Mehrani et al. [45] concluded that most of the electrostatic charge in a fluidized bed was related to the charges entrained by the finest particles. More recently, Moughrabiah et al. [46] studied the effect of pressure, temperature and gas velocity on the electrostatics of a 3D column with a diameter of $15 \mathrm{~cm}$, and evaluated the same particles fluidized by Park et al. [44] (glass and polyethylene). The results obtained from both types of particles were compared, and the authors demonstrated that the glass particles accumulated more electrostatic charge than the plastic particles. Moughrabiah et al. [46] suggested that electrostatic charges can modify interparticle forces, which could have a significant effect on the properties of the bed, such as the effective viscosity. In $2 \mathrm{D}$ beds, walls particle interactions could influence the electrostatic charge; however, these effects are usually neglected in 3D beds[42]. Thus, electrostatic charge could be considered in the momentum equation (Eq. (3)), but the multitude of variables and the experimental conditions of the data summarized in Table 3 preclude the quantification of this force. Kashyap et al. [47] studied the effect of an electric field on the hydrodynamics of particles in a rectangular fluidized bed. Thus, if the electrostatic forces can be quantified, the effects of an electric field could be included in the correlation as a term that increases the gas pressure drop along the bed.

According to criteria proposed by Grace, most of the data shown in Fig. 5 correspond with type B particles [36]. Alternatively, Glicksman and McAndrews [34] used type D particles, and the polystyrene spheres fluidized by Mudde et al. [35] are similar to type A particles. However, the particles used by Mudde et al. are considered type B. Rowe and Everett [23] did not indicate the density of the alumina particles used in their study; thus, the particle type could not be determined.

Based on the experimental conditions shown in Table 3, another parameter that may affect the bed dynamics is the sphericity $\phi_{p}$ of the particles [24]. The particle sphericity is directly related to the particle 
shape; thus, because internal friction can alter fluidized bed behavior, the effect of particle shape on the angle of internal friction of fine particles must be considered if the experiments are based on different types of particles [48]. Most of the results that are in accordance with Eq. (5) were based on spherical particles $\left(\phi_{p}=1\right)$. In contrast, most of the experiments represented by filled symbols were based on non spherical particles $\left(\phi_{p} \neq 1\right)$. Only the data obtained by Mudde et al. [35] were based on spheres; however, these particles were made of plastic material, and electrostatic charge had a significant impact on the results. The particle sphericity is difficult to measure, and most of the experimental results in the literature are based on indirect measurements from the Ergun equation [49], thus, the uncertainty of the results is high. As a result, Eq. (2) should be used cautiously when non spherical particles and/or particles that do not belong to group B are fluidized because the values of $\mathrm{a}$ and $\mathrm{b}(a=8.5$ and $b=1.6$, respectively) are based on spherical type $\mathrm{B}$ particles.

\subsection{Critical bed thickness}

Eq. (2) suggests that the minimum fluidization velocity in a 2D fluidized bed and the minimum fluidization velocity in a 3D bed are related when electrostatic forces are not present in the fluidization process and atmospheric air is used as a fluidizing agent. Under these conditions, the proposed correlation can be used to estimate the critical bed thickness $t^{*}$, which is defined as the minimum bed thickness that results in negligible wall effects on the minimum fluidization velocity of a 2D bed. Thus, $t^{*}$ can be obtained from Eq. (2) with $U_{m f, 2 D} / U_{m f, 3 D}=1.01$. Fig. 10 shows the variation in the critical bed thickness as a function of the particle size of type B particles, according to Geldart's classification [30]. Namely, if the value of $t^{*}$ is two orders of magnitude greater than the particle size $\left(t / d_{p} \sim 100\right)$, wall effects can be neglected.

Nevertheless, $t^{*}$ only considers the effect of the walls on the minimum fluidization velocity. Other parameters typically measured in a $2 \mathrm{D}$ bed (pressure fluctuations, bubble distribution, bubble size and velocity, gas and particle motion, etc.) may differ from those obtained in a 3D bed for values of $t \gtrsim t^{*}\left[\begin{array}{ll}22 & 25\end{array}\right]$.

\section{Conclusions}

A correlation for the prediction of the minimum fluidization velocity in $2 \mathrm{D}$ fluidized beds was proposed. The equation was obtained by fluidizing spherical particles in a 2D bed and varying the bed thickness (between 0.5 and $2.0 \mathrm{~cm}$ ) and the fixed bed height

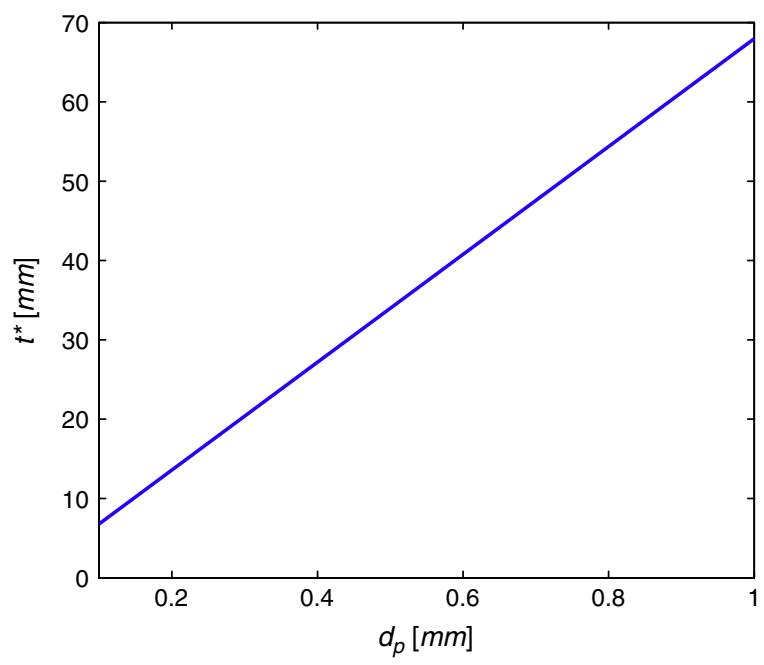

Fig. 10. Variation of the critical bed thickness $t^{*}$ with the particle size $d_{p}$. (between 10 and $30 \mathrm{~cm}$ ). The results indicated that wall effects on the minimum fluidization velocity can be neglected when the bed thickness to particle size ratio is $t / d_{p}>100$. Nevertheless, when the proposed correlation was applied to the results of other studies, the correlation properly predicted the minimum fluidization velocity of spherical particles in a 2D bed made of glass walls. Alternatively, when the bed is made of plastic walls, electrostatic charge can have a significant effect on $U_{m f}$ and the experimental results were not in agreement with the proposed correlation. In addition, Jackson's model for wall effects was fitted to the experimental fluidization defluidiza tion curves. Although the parameters of the model can be adjusted to a specific experiment, due to the one dimensional assumptions of the model, general conclusions on the determination of the minimum fluidization in 2D fluidized beds cannot be made.

\section{Notation}

\section{Latin letters}

$\begin{array}{ll}A & \text { Section of the bed perpendicular to the gas flow }\left[\mathrm{m}^{2}\right] \\ D_{h} & \text { Hydraulic diameter }[\mathrm{m}] \\ d_{p} & \text { Particle size }[\mathrm{m}] \\ F & \text { Constant in Eq. }(4)[\mathrm{Pa}] \\ H & \text { Bed height }[\mathrm{m}] \\ h & \text { Fixed bed height }[\mathrm{m}] \\ J & \text { Constant defined in Eq. }(8)\left[\mathrm{m}^{1}\right] \\ j & \text { Janssen coefficient }[-] \\ t & \text { Bed thickness }[\mathrm{m}] \\ t^{*} & \text { Critical bed thickness }[\mathrm{m}] \\ g & \text { Gravity constant }\left[9.81 \mathrm{~m} / \mathrm{s}^{2}\right] \\ U & \text { Superficial gas velocity }[\mathrm{m} / \mathrm{s}] \\ U_{m f} & \text { Minimum superficial gas velocity }[\mathrm{m} / \mathrm{s}] \\ u_{c} & \text { Critical gas velocity }[\mathrm{m} / \mathrm{s}] \\ u_{g} & \text { Interstitial gas velocity }[\mathrm{m} / \mathrm{s}] \\ v_{t} & \text { Particle terminal velocity }[\mathrm{m} / \mathrm{s}] \\ w & \text { Width of the bed }[\mathrm{m}] \\ x & \text { Horizontal coordinate } \\ z & \text { Vertical coordinate, measured from the top of the bed }\end{array}$

\section{Greeks letters}

$\Delta P \quad$ Gas pressure drop due to the particles $\Delta P=\Delta P_{s+p}-\Delta P_{s}$ $[\mathrm{Pa}]$

$\Delta P_{\text {dist }} \quad$ Gas pressure drop in the distributor $[\mathrm{Pa}]$

$\Delta P_{g} \quad$ Gas pressure drop including wall effects (Eq. (7)) $[\mathrm{Pa}]$

$\Delta P_{s} \quad$ Gas pressure drop in the empty system $[\mathrm{Pa}]$

$\Delta P_{s+p} \quad$ Gas pressure drop in the system filled with particles $[\mathrm{Pa}]$

$\varepsilon \quad$ Voidage in the bed $[-]$

$\mu \quad$ Friction coefficient [-]

$\rho_{s} \quad$ Solid density $\left[\mathrm{kg} / \mathrm{m}^{3}\right]$

$\sigma_{s} \quad$ Compressive yield stress of the particles $[\mathrm{Pa}]$

$\phi \quad$ Particle concentration $\phi=1-\varepsilon[-]$

$\phi_{p} \quad$ Particle sphericity [-]

Subscripts
( ) $\begin{array}{ll}\text { D } & \text { Magnitude refereed to the 2D bed } \\ \text { ( ) } & \text { Magnitude refereed to the 3D bed } \\ \text { ( ) } & \text { Defluidization curve } \\ \text { ( ) } & \text { Fluidization curve } \\ \text { ( ) } & \text { Minimum } \\ \text { ( ) } \max & \text { Maximum }\end{array}$




\section{Acknowledgement}

This work has been partially funded by the Spanish Government (Project DPI2009 10518) and the Autonomous Community of Madrid (Project S2009/ENE 1660). Their supports are greatly appreciated.

\section{References}

[1] N.P. Cheremisinoff, Review of experimental methods for studying the hydrodynamics of gas-solid fluidized beds, Industrial and Engineering Chemistry Process Design and Development 25 (1986) 329-351.

[2] J. Werther, Measurement techniques in fluidized beds, Powder Technology 102 (1999) 15-36.

[3] J.R. van Ommen, R.F. Mudde, Measuring the gas-solids distribution in fluidized feds - a review, International Journal of Chemical Reactor Enginerring 6 (2008), Review R3.

[4] S.J.R. Simons, Imaging techniques for fluidized bed systems: a review, Chemica Engineering Journal and the Biochemical Engineering Journal 56 (1995) 83-93.

[5] C.R. Müller, D.J. Holland, A.J. Sederman, M.D. Mantle, L.F. Gladden, J.F. Davidson, Magnetic resonance imaging of fluidized beds, Powder Technology 183 (2008) 53-62.

[6] D.J. Holland, C.R. Müller, A.J. Sederman, M.D. Mantle, L.F. Gladden, J.F. Davidson, Magnetic resonance imaging of fluidized beds: recent advances, Theoretical Foundations of Chemical Engineering 42 (2008) 469-478.

[7] A.C. Rees, J.F. Davidson, J.S. Dennis, P.S. Fennell, L.F. Gladden, A.N. Hayhurst, M.D. Mantle, C.R. Muller, A.J. Sederman, The nature of the flow just above the perforated plate distributor of a gas-fluidised bed, as imaged using magnetic resonance, Chemical Engineering Science 61 (2006) 6002-6015.

[8] L. Massimilla, J.W. Westwater, Photographic study of solid-gas fluidization, AIChE Journal 6 (1960) 134-138.

[9] P.N. Rowe, B.A. Partridge, E. Lyall, Cloud formation around bubbles in gas fluidized beds, Chemical Engineering Science 19 (1964) 973-985.

[10] P.N. Rowe, B.A. Partridge, An X-ray study of bubbles in fluidised beds, Transactions of the Institution of Chemical Engineers 43 (1965) 157-175.

[11] J.R. Grace, D. Harrison, The behaviour of freely bubbling fluidised beds, Chemical Engineering Science 24 (1969) 497-508.

[12] B. Trisakti, J. Oshitani, Z. Tanaka, Circulating particle flow and air bubble behavior at various superficial gas velocities in two-dimensional gas-solid fluidized beds, Advanced Powder Technology 12 (2001) 507-519.

[13] D. Pallarès, F. Johnsson, A novel technique for particle tracking in cold 2 dimensional fluidized beds-simulating fuel dispersion, Chemical Engineering Science 61 (2006) 2710-2720.

[14] L. Shen, F. Johnsson, B. Leckner, Digital image analysis of hydrodynamics twodimensional bubbling fluidized beds, Chemical Engineering Science 59 (2004) 2607-2617.

[15] A. Busciglio, G. Vella, G. Micale, L. Rizzuti, Analysis of the bubbling behaviour of 2D gas solid fluidized beds Part I. Digital image analysis technique, Chemical Engineering Journal 140 (2008) 398-413.

[16] D. Santana, S. Nauri, A. Acosta, N. García, A. Macías-Machín, Initial particle velocity spatial distribution from 2-D erupting bubbles in fluidized beds, Powder Technology 150 (2005) 1-8.

[17] C.R. Müller, J.F. Davidson, J.S. Dennis, A.L. Hayhurst, A study of the motion and eruption of a bubble at the surface of a two-dimensional fluidized bed using particle image velocimetry (PIV), Industrial \& Engineering Chemistry Research 46 (2007) 1642-1652.

[18] J.A. Almendros-Ibáñez, S. Sánchez-Delgado, C. Sobrino, D. Santana, Experimental observations on the different mechanisms for solid ejection in gas-solid fluidized beds, Chemical Engineering and Processing 48 (2009) 734-744.

[19] J.A. Almendros-Ibáñez, D. Pallarès, F. Johnsson, D. Santana, Novel approach to characterize fluidized bed dynamics combining particle image velocimetry and finite element method, Industrial \& Engineering Chemistry Research 48 (2009) 5010-5023.

[20] J. Link, C. Zeilstra, N. Deen, H. Kuipers, Validation of a discrete particle model in a 2D spout-fluid bed using non-intrusive optical measuring techniques, Canadian Journal of Chemical Engineering 82 (2004) 30-36.
[21] A. Busciglio, G. Vella, G. Micale, L. Rizzuti, Analysis of the bubbling behaviour of 2D gas solid fluidized beds. Part II. Comparison between experiments and numerical simulations via digital image analysis technique, Chemical Engineering Journal 148 (2009) 145-163.

[22] J.R. Grace, J. Baeyens, in: D. Geldart (Ed.), Gas Fluidization Technology, Wiley, Chichester, 1986, p. 415.

[23] P.N. Rowe, D.J. Everett, Fluidised bed bubbles viewed by X-rays. Part II - the transition from two to three dimensions of undisturbed bubbles, Transactions of the Institution of Chemical Engineer 50 (1972) 49-54

[24] D. Geldart, The size and frequency of bubbles in two- and three-dimensional gasfluidised beds, Powder Technology 4 (1970) 41-55.

[25] R. Clift, in: D. Geldart (Ed.), Gas Fluidization Technology, Wiley, Chichester, 1986, p. 53.

[26] J.V. Briongos, J. Guardiola, Newmethodology for scaling hydrodynamic data from a 2D-fluidized bed, Chemical Engineering Science 60 (2005) 5151-5163.

[27] G. Ramos Caicedo, M. García Ruiz, J.J. Prieto Marqués, J. Guardiola Soler, Minimum fluidization velocities for gas/solid 2D beds, Chemical Engineering and Processing 41 (2002) 761-764.

[28] R. Jackson, in: L.S. Fan, T.M. Knowlton (Eds.), Fluidization IX: Proceedings of the Ninth Engineering Foundation Conference of Fluidization. New York, 1998, p. 1.

[29] S. Sánchez-Delgado, C. Marugán-Cruz, A. Acosta-Iborra, D. Santana, Dense phase velocity fluctuation in a 2-D fluidized bed, Powder Technology 200 (2010) 37-45.

[30] D. Geldart, Types of gas fluidization, Powder Technology 7 (1973) 285-292.

[31] C. Sobrino, J.A. Almedros-Ibáñez, D. Santana, M. de Vega, Fluidization of group B particles with a rotating distributor, Powder Technology 181 (2008) 273-280.

[32] D.G. Kathuria, S.C. Saxena, A variable-thickness two-dimensional bed for investigating gas-solid fluidized bed hydrodynamics, Powder Technology 53 (1987) 91-96.

[33] S.C. Saxena, S. Jadav, A two-dimensional gas fluidized bed for hydrodynamic and elutriation studies, Powder Technology 36 (1983) 61-70.

[34] L.R. Glicksman, G. McAndrews, The effect of bed width on the hydrodynamics of large particle fluidized beds, Powder Technology 42 (1985) 159-167.

[35] R.F. Mudde, H.B.M. Schulte, H.E.A. van den Akker, Analysis of a bubbling 2-D gasfluidized bed using image processing, Powder Technology 81 (1994) 149-159.

[36] J.R. Grace, Contacting modes and behaviour calssification of gas-solid and other two-phase suspensions, Canadian Journal of Chemical Engineering 64 (1986) 353-363.

[37] R. Jackson, The Dynamics of Fluidized Particles, Cambridge University Press, 2000.

[38] A. Srivastava, S. Sundaresan, Role of wall friction in fluidization and standpipe flow, Powder Technology 124 (2002) 45-54.

[39] P.N. Loezos, P. Costamagna1, S. Sundaresan, The role of contact stresses and wall friction on fluidization, Chemical Engineering Science 57 (2002) 5123-5141.

[40] X. Liu, G. Xu, S. Gao, Micro fluidized beds: wall effect and operibility, Chemical Engineering Journal 137 (2008) 302-307.

[41] S. Sánchez-Delgado, J.A. Almendros-Ibáñez, A. Soria-Verdugo, D. Santana, U. RuizRivas, in: J. Werther, W. Nowak, K.E. Wirth, E.U. Hartge (Eds.), TuTech Innovation GmbH, Hamburg, 2008, p. 1007.

[42] V. Rojo, J. Guardiola, A. Vian, A capacitor model to interpret the electric behaviour of fluidized beds. Influence of apparatus geometry, Chemical Engineering Science 41 (1986) 2171-2181.

[43] J. Guardiola, V. Rojo, G. Ramos, Influence of particle size, fluidization velocity and relative humidity on fluidized bed electrostatic, Journal of Electrostatics 37 (1996) $1-20$.

[44] A.H. Park, H. Bi, J.R. Grace, Reduction of electrostatic charges in gas-solid fluidized beds, Chemical Engineering Science 57 (2002) 153-162.

[45] P. Mehrani, H. Bi, J.R. Grace, Electrostatic charge generation in gas-solid fluidized beds, Journal of Electrostatics 63 (2005) 165-173.

[46] W.O. Moughrabiaj, J.R. Grace, H. Bi, Effects of pressure, temperature, and gas velocity on electrostatics in gas-solid fluidized beds, Industrial \& Engineering Chemistry Research 48 (2009) 320-325.

[47] M. Kashyap, D. Gidaspow, M. Driscoll, Effect of electric field on the hydrodynamics of fluidized nanoparticles, Powder Technology 183 (2008) 441-453.

[48] K. Shinohara, M. Oida, B. Golman, Effect of particle shape on angle of internal friction by triaxial compression test, Powder Technology 107 (2000) 131-136.

[49] D. Kunii, O. Levenspiel, Fluidization Engineering, 2nd editionButterworthHeinemann, 1991. 